\title{
Contemporary Trends in Quality Assurance in Distance Education
}

\author{
Shahzada Masoud ul Hassan Bukhari \\ PhD Scholar \\ Mohi-ud-Din Islamic University, Nerian Sharif, AJ\&K \\ shahzada.mh@gmail.com \\ Dr. Nazir Haider Shah \\ HOD, Department of Education \\ Mohi-ud-Din Islamic University, Nerian Sharif, AJ\&K \\ Prof. Dr. Lt Col (Retd) Manzoor Hussain Arif \\ Professor of Education \\ Pir Mehr Ali Shah Arid Agriculture University, Rawalpindi
}

\begin{abstract}
With the emergence of day-by-day increasing distance learning institutions worldwide, the question of quality assurance (QA) in distance education (DE) needs to be addressed at appropriate level. The objective of this paper was to examine various QA practices undertaken by several QA regulatory bodies and existing models in distance and online education being followed globally. The researcher undertook extensive review of related literature pertaining to QA practices worldwide to reach at a common ground that how a DE institution be dealt in relation to its QA needs. The paper highlighted that prevailing QA models in distance and online learning have been developed in response to specific demands of stakeholders to ensure transparency and improved attention towards learning outcomes, that means a single model is not likely to fulfil the needs of all stakeholders. The paper also emphasised that it will neither be appropriate nor admissible to prefer and recommend one system of QA to another since the selection mostly depends on the efficacy and relevance of model to the specific needs, aims and maturity of educational institutions. In addition, the paper provided a comparative review of research on the effectiveness of QA practices in DE. Some recent studies reviewed in this paper highlighted the similar nature of benchmarks or dimensions for an external QA system for distance and online programs with minor variations on account of institutional local needs. However, due to technological developments external QA instruments may need revision to deal current standards and best practices.
\end{abstract}

Keywords: Distance education, higher education, external quality assurance mechanism, technological developments.

\section{Introduction}

Distance and online education, being a flexible mode of education is attracting students worldwide. As a result, many conventional universities in Asia have been offering DE programmes to enhance the revenues since the start of $20^{\text {th }}$ century. A study undertook in 2009 reflected increased trend of offering dual mode of education programmes by conventional universities in Asia (Latchem \& Jung, 2009). It is very obvious to understand that the volume of online education 
programmes in Asia could have increased manifold by 2020.Thus with the fast-growing reliance on online institutions, the apprehensions of Asian community regarding quality assurance issues, have also increased profoundly. QA in distance learning is a vast topic and due to COVID-19 pandemic the world has started realizing the importance of online education more than before. 98 $\%$ of Indonesian HE sector has already shifted to online education due to COVID-19 outbreak (Belawati \& Nizam, 2020; Nizam, 2020). Most of the distance and online education providers in Asia alone are responding to the need of appropriate and effective quality assessment systems for DE programmes (Insung, Tat, Chen, Sanjaa, \&Tian, 2011).

Quality has also become strategically important in all domains of higher education programmes. Because of increasing worldwide competition in education sector students as well as community in $21^{\text {st }}$ century look for quality education but at a lower cost. With the emergence of day-by-day increasing distance learning institutions worldwide, students hardly differentiate between formal and non-formal education system nowadays. The figure of students opting for studies in distance and online programs has gone multiplied in previous years. In order to satisfy the requirements of the student's various universities are doing their level best to ensure quality in distance learning courses. Darojat, Nilson, \&Kaufman (2015) are of the view that execution of QA programs in distance learning courses is very challenging and calls for tough resolve of the top administration and officials at all ranks. Various aspects like leadership's opinion and culture of institution about the quality assessment and assurance play vital role in making QA system successful ( Brunetto \& Farr-Wharton, 2005).

QA is comparatively a new idea for most of the states, and various researches highlight that there exist many queries about the relevance of QA procedures for online courses. First, the efficacy or usability of prevailing QA models need to be determined (Brittingham, 2008). Secondly, their equal usefulness across national boundaries needs to be questioned (Reisberg, 2007). Students' expectations from educational institutions can only be met if their concern for quality in education is addressed effectively, moreover, they ask for value for their money in all areas of their interaction with education providers. Students' expectations of high-quality education at lower cost have resulted in competitive tuition fee structures, to be formulated at institutional level, which has created fiscal issues for many educational institutions. It suggests that higher education sector needs substantial re-engineering in the delivery of educational services (Ramdass \& Nemavhola , 2018).

Evaluating online programmes on the pattern of formal mode of education is not recommended because the former is altogether different form the later in terms of its structure and working, and for the same reason quality assurance models for conventional education programs cannot be practiced for distance and online education courses.(Jung \& Latchem, 2012; Veytia \& Chao González, 2013).Assuring quality in higher education, may it be a formal or virtual mode of learning, is a challenging task and demands time, resources, commitment at all levels as well as huge documentation by the faculty in an institution (Darojat,2018). QA Toolkit for DE highlighted the aspect of significance of accreditation and assessment of educational programmes and related it with public satisfaction to build their trust that the degree offered by online education providers meets acceptable academic and professional standards (Commonwealth of Learning, 2009).

A study undertaken by Darojat (2018) in Universitas Terbuka Jakarta, Indonesia emphasised the need of strong commitment, effort and active participation of institutional staff from top to bottom to implement and fulfil the criteria of quality assurance in a virtual programme. It was also revealed that ensuring quality in a programme is the responsibility of everybody in an institution. Academic and administrative staff at all levels needs to contribute towards quality 
assurance process. Number of distance and online education providers globally have established standards and procedures to ensure quality in virtual programmes (Insung, et al., 2011).

\subsection{Quality Assurance in Distance Education}

The Information and Communication Technology (ICT) has changed the paradigm in relation to many aspects of distance and online education. The biggest example is incorporation of the technology-based $5^{\text {th }}$ generation (Taylor 2001) model that provides flexibility and student friendly DE and literally replaced earlier print-based and multi-media delivery methods.

There is a major drawback in evaluating an online program in this manner since DEis altogether different from formal system of education in the terms of its structure and working. DE is not comparable to conventional models, and as a result the quality assessment systems and models should not be applied to both categories of education (Jung \& Latchem, 2012; Veytia \& Chao González, 2013).QA Toolkit for DE stated that accreditation and assessment mechanism are required to satisfy the public and build their trust that the degrees offered by distance learning institutions meet adequate academic and professional criteria (Commonwealth of Learning, 2009).

May it be a formal system or non-formal mode of education, ensuring quality, demands commitment at all levels in an institution. In some cases, the implementation of QA programs in distance learning providing institutions have been perceived too challenging and time consuming, since it demands huge documentation (Darojat, 2018). A collective case study, recently conducted on comparative analysis of implementation of QA systems, reveals that quality starts with inner self and is multi-dimensional (Zuhairi, Maria, Mir, 2020).

A study undertaken by Darojat (2018) in Universitas Terbuka Jakarta, Indonesia discovered that top academic and administrative staff believed that implementation of quality assessment mechanism in any distance learning institution requires strong commitment, effort and active participation from top to bottom. It was also recommended that all staff must accept their responsibly and undertake their role to contribute towards QA processes.

\subsection{Objectives of Study}

The aim of this article was to examine various QA practices undertaken by various QA regulatory bodies and existing models in distance and online education being followed globally, with a view to attain a common understanding regarding implementation of a QA mechanism, if required at a DE institution. The comparative analysis of QA practices in distance and online education would develop a vivid picture for the stakeholders to reach better understandings in QA issues.

\section{Literature Review}

Numerous establishments, operating in distance and online education, located in various countries have established principles, procedures, or yardsticks to ensure quality of distance and virtual education (Insung et al., 2011).

\subsection{International Perspective of Quality Assurance in Distance Education}

Some of the significant systems of QA, operating in DE worldwide, have been reviewed in the following lines.

\subsection{United States of America}

The Institute for Higher Education Policy of USA, with a view to assure quality in distance and online education, has formulated a system based on 24 benchmarks that deal with seven 
aspects and consider them essential to maintain excellence in internet-based distance learning. These benchmarks include, Institutional Support, Course Development, Teaching/Learning, Course Structure, Student Support, Faculty Support and Evaluation and Assessment (IHEP 2000).

The federal as well as state governments in USA are convinced to address quality assurance challenges in distance learning programs. As a result, the regional regulatory bodies in collaboration with Council of Higher Education Accreditation (CHEA) are in the process of reviewing their criterion, regarding quality assurance, in order to include distance learning courses into their evaluation procedures (CHEA, 2007).

The regional accreditation commissions have finalized specific standards that are being implemented to evaluate distance learning programs. These standards are comprised of five major areas each corresponding to a specific part of institutional act and each of which addresses a specific area of institutional operation relevant to distance education. These standards include: "institutional context and commitment, curriculum and instruction, faculty support, student support and evaluation and assessment" (CHEA, 2007).

\subsection{United Kingdom}

Open \& Distance Learning Quality Council of UK is responsible for QA in DE programs and published the guidelines for distance learning in higher education. The guidelines have been formulated under six headings: “(1) System design, (2) Program design, approval and review, (3) The management of program delivery, (4) Student development and support, (5) Student communication and representation, (6) Student assessment." Each area addresses an aspect of quality assurance in a comprehensive manner. Peer-led quality assessment through the Quality Assurance Agency (QAA) is followed in UK to assure quality in DE. The quality benchmarks, used as part of external quality mechanism, have been taken from the "Business Excellence Model developed by the European Foundation for Quality Management” (ODLQC, 1995).

\subsection{China}

Higher Education Department of Ministry of Education serves as the agency to manage all aspects of distance education in China. The Higher Education Department carries out most of the management, evaluation, and supervision of the entire system of distance and virtual education. Modern DE pilot project for DE in China has formed five elements for assuring quality, which are, teaching resource, controlling of the learning process, learning support and services, teaching administration and operation of Radio and Television Universities (RTVUs) system (Wancai,2008).

\section{$2.5 \quad$ India}

India's biggest open university, "The Indira Gandhi National Open University" (IGNOU), was established in 1985. IGNOU's current enrolment of students is over 3.5 million. During last two decades, about 13 more state owned open universities have been established that caters for 25 $\%$ of total enrolment in higher education sector. The QA in distance and open institutions in India is the responsibility of The Distance Education Council (DEC) of India. DEC offers rules and standards for assessment and accreditation in DE. Any student who qualifies from distance and open institutions in India gets prior certification and approval of degree from DEC to get employment in any government department (DEC, 1991).

\subsection{Indonesia}

Indonesia is also one of the major operators of DE in higher education sector in Asia. Indonesia uses its DE institutions initially to run courses for teachers' training and this practice is 
in vogue since mid-1950s. However, DE was widely accepted and recognized in Indonesia once University Terbuka (UT) was established in 1984. Though Ministry of National Education in Indonesia extended its permission to all formal conventional universities to offer DE courses since 2001, nevertheless, UT is the only and biggest university that completely employ on to open and DE system in Indonesia. In 2010 UT's total strength was over 650,000. UT, being a public university is subject to follow and implement all quality benchmarks and rules related to $\mathrm{HE}$ institutions in Indonesia. (BAN-PT, 1994).

\subsection{Quality Assurance Models in Virtual Education}

i. "QMCBAAF- (Quality Model Certification Benchmarking Accreditation Advisory Framework)."

ii. "ACDE - (The African Council for Distance Education Quality Assurance and Accreditation Agency)."

iii. "ACODE - (The Australasian Council of Open, Distance and eLearning)."

iv. "AVU - (The African Virtual University)."

v. "CALED- (The Latin American and Caribbean Institute for Quality in Distance Education)."

vi. "CHEA (The Council for Higher Education Accreditation), US."

vii. "E-xellence EADTU- (The European Association of Distance Teaching Universities),NL."

viii. "OpenupEd EADTU - (The European Association of Distance Teaching Universities),NL."

ix. "UNIQUe EFQUEL - (The European Foundation for Quality in eLearning), BE."

X. "ECB Check EFQUEL - (The European Foundation for Quality in eLearning). From Dec 2014 GIZ (Deutche Gesellshaft fur International Zuzammenarbeit), DE."

xi. "The eLearning Guidelines - (eLg) Ako Aotearoa, developed by Tertiary Education Commission, led by AUT University and Massey University, New Zealand."

xii. "The E-Learning Maturity Model- (eMM) New Zealand Ministry of Education Tertiary E-Learning Research Fund."

xiii. "E-learning Quality Model - (ELQ) NAHE (The Swedish National Agency for Higher education)."

xiv. "Epprobate The Learning Agency Network- (LANETO e V), DE."

$\mathrm{xv}$. "Khan eight-dimensional eLearning framework Badrul Khan."

xvi. "The OLC Quality Scorecard Online Learning Consortium - (former Sloan-C), US."

xvii. "OER TIPS- "The Commonwealth Educational Media Centre for Asia (CEMCA)."

xviii. "Pick \& Mix - (Matic Media, SERO Consulting Ltd, UK)."

The worth of aforesaid quality assurance models cannot be denied, nonetheless, there exists variation in relation to the number of benchmarks in each model. Moreover, we do not find any common dimension in above given models. None of the models mentioned above emphasized the need for the evaluation of quality of programmes nor catered for the quality of planning, execution, and results in distance education programmes. There exists remarkable variation among authors of models in relation to the concept of dimension, its interpretation and use of methodology in this regard. 


\subsection{Review of Current Researches on QA in DE}

A study conducted by ICDE, "International Council for Open and Distance Education" in 2015 analysed more than 40 quality standard models or guidelines from regulatory QA bodies of the world(Ebba Ossian Nilsson, Keith Williams, Anthony F. Camilleri, and Mark Brown, 2015). The most common mechanism of QA in distance and online education found in the review was pertaining to three most general performance categorization of activities. First is, "management" that deals with the institutional strategy, visions, and resourcing whereas second is pertaining to, "products" that involves the processes of curriculum and module development. The third performance category is related to, "services" that means student, staff support and information resources etc.

The researcher also found variation regarding number of performance evaluation indicators or benchmarks ranging from 20 to 100 in number. It was also revealed that the models were developed keeping in view the varied purposes in different contexts at different times. It is hardly admissible to prefer one model to another because selection of QA model depends on the usability and application of model to the specific needs, aims and maturity of educational institutions (Ebba, Keith, Anthony, Camilleri, Mark,2015).

Spanish universities offering distance and online education are also facing challenge of ensuring quality in their programmes nowadays. A study undertaken in Barcelona university in 2018 with the objective of developing a QA model for DE revealed that there exists exceptionally huge diversity of quality tools being practiced by distance and online education universities. The researcher found hardly any gap to be analysed in institutional QA mechanisms that may become a base to develop a new set of arrangement. The researcher, eventually, developed an integrative model consisted of two variables, 14 dimensions and 81 quality indicators. The quality of online programme was first variable whereas second variable was about ongoing assessment of on online programme.

The integrated quality evaluation model suggested in this study had 14 dimensions which include, "program justification, program objectives, student profile, thematic contents of the elearning program, learning activities, online teacher profile, educational material, educational strategies, tutoring, assessment of students' learning, virtual platform, initial assessment of the program, process assessment of the program and final assessment of the program" (Renata, 2018 p. 21-22).

The University of Nebraska at Kearney (UNK) with a view to assess quality of online courses decided to follow Chico's Rubric for Online Instruction (ROI) of California University as a baseline to develop an evaluation instrument for online courses (Steven J, McGahan, Christina, Karen, 2015). The ROI covered six areas of development, including, "learner support and resources; online organization and design; instructional design and delivery; assessment and evaluation of student learning; innovative teaching with technology; and faculty use of student feedback" (Steven J. et al., 2015 p.130). Lesson learnt was, using a prebuilt instrument for course evaluation may be a better option but a careful analysis of instrument is recommended before the decision to opt for a particular instrument for a campus is reached upon(Steven J. et al., 2015).

\section{Research Methodology}

The researcher undertook literature review for this paper by analysing various global QA practices undertaken by different QA regulatory bodies and studying different QA models being implemented by various stakeholders in DE field. The researcher also made comparative analysis 
of current studies conducted on the same subject to develop a vivid picture for better comprehension for policy makers. The lessons learnt in this regard formulated a concrete basis for the stakeholders to view complex issues of QA in distance and online education in the right context.

\subsection{Data Collection and Analysis}

The researcher undertook an elaborate review of existing QA practices in vogue at various leading universities of the world and made an endeavour to compare various models in relation to their quality benchmarks and corresponding quality indicators to develop a broader sketch to deal with the challenge that how quality in DE institutions be met appropriately. The inclusion of international, comparative analysis component has been made to characterize this paper from what might have been a narrower focus on national and institutional models. The researcher tried to develop a broader perspective to make a bigger contribution to the literature and the professional field of comparative educational policy formulation for external quality issues in online/distance education.

\section{Discussion}

There is an exceptionally huge diversity of quality tools being used by distance and virtual education providers. There hardly exists any gap in relation to analysis of institutional systems that may pose a demand to develop a new scheme. Moreover, it takes considerable amount of time and resources to construct a course evaluation instrument, however, some best practices to reduce time in this regard can be summarized in these words. Using a pre-built instrument, if it fulfils the needs of your institution, can be a better option, however, a careful analysis of instruments is recommended before deciding to pick a particular instrument for a campus. Developing an instrument for a particular university or college may be a very good choice in case the task is completed with much care and deliberation. The instrument that is selected for implementation should be easy to use by faculty members and related staff.

\section{Conclusion}

This paper briefly highlighted salient features of QA systems being implemented to assess quality in DE globally. Assuring quality in DE is a challenging task and require total commitment of academic as well as administrative staff in an institution to make the QA mechanism a success. Having reviewed the existing QA models in virtual education, it is concluded that most of the QA models have been developed keeping in view the specific needs of the stakeholders, which means a sole model may not be able to fulfil the needs of all institutions. Cultural and institutional contexts need to be kept into consideration while adopting a QA model by distance learning institutions in developing countries and if needed, modification in design can also be made. Almost all QA models have definite paucities like lack of the element of global applicability, lack of clarity, maturity levels they are best for, widely different quality of reviews and of guidance given, challenges to respond to the change, etc. Some recent studies reviewed in this paper also highlighted that various QA models in DE has similar type of benchmarks or dimensions, nonetheless, in consideration of continuous technological advancements, QA system may need revision to cater for contemporary standards and practices. 


\section{References}

BAN-PT (n.d.) National Accreditation Board for Indonesian Higher Education website. Retrieved March 7, 2007 from: http://www.ban-pt.or.id/ (page 27)

Belawati, T. and Nizam (Eds) (2020), Potret Pendidikan Tinggi di Masa Covid-19 (The Portrait of Higher Education during Covid-19), Direktorat Jenderal Pendidikan Tinggi, Jakarta, available at: http://repository.ut.ac.id/9010/.

Brunetto, Y., \& Farr-Wharton, R. (2005, July). Academics' responses to the implementation of a quality agenda. Quality in Higher Education, 11(2), 161-180.

CHEA, Glossary: Council for Higher Education Accreditation Retrieved from: https://www.chea.org/accreditation-and-quality-assurance-glossary

Commonwealth of Learning,2007: Quality Assurance Toolkit for Distance Higher Education Institutions and Programmes,ttps://open.saide.ngo/repository/opensaide

Darojat Ojat., Nilson Michelle \&Kaufman David(2018)Indonesia's Universitas Terbuka Quality Assurance in Asian Open and Distance Learning: Policies and Implementation VOL. 2, No. 1Retrieved from: https://j14d.org/index.php/ej14d//article/view/105/96

DEC, Distance Education Council (India), 1991, www.ugc.ac.in.

Ebba Ossiannilsson, Keith Williams, Anthony F. Camilleri, and Mark Brown with association of European Association of Distance Teaching Universities - EADTU. -2015

ICDE, International Council for Open and Distance Education Lilleakerveien 230283 Oslo Norway

IIEP (2000). International Institute of Educational Planning. Medium-Term Plan:2008-2013. Paris: IIEP - UNESCO. Valderrama, F. (1995) A History of UNESCO. Paris: UNESCO

Insung, Tat, Chen, Sanjaa, \&Tian, (2011) Quality Assurance in Asian Distance Education:

Diverse Approaches and Common Culture The International Review of Research in Open and Distance Learning-IRRODL Vol 12, No 6 (2011)

Jung, I., \& Latchem, C. (2012). Quality assurance and accreditation in distance education and online. New York/London: Routledge.

Latchem, C., \& Jung, I. S. (2009). Distance and blended learning in Asia. New York and London: Routledge.

Nizam (2020), "Potret transformasi digital: mendadak daring (The portrait of digital transformation: suddenly going into the networked learning)", in Belawati, T. and Nizam (Eds), Potret Pendidikan Tinggi di Masa Covid-19 (The Portrait of Higher Education in the Covid-19 Era), DirektoratJenderal Pendidikan Tinggi Kementerian Pendidikan dan Kebudayaan, Jakarta, pp. 31-44, available at: http://repository.ut.ac.id/9010/.

ODLQC -1969 The Open and Distance learning Quality Council, UK, Retrieved from: https://www.academia.edu/12739846/Assessment_and_Accreditation_of_ Open_and_Distance_Learning 
Quality Assurance Toolkit for Distance Higher Education Institutions and Programs Commonwealth of Learning 2009, https//open.saide.ngo/repository/01\% 20COL \%20HE_QA_Toolkoit_web.pdf From: http://qec.quest.edu.pk/hec-proforma

Ramdass Kemlall \& Nemavhola Fulufhelo, (2018), Department of Mechanical and Industrial Engineering University of South Africa Pretoria, South Africa Quality Practices: An Open Distance Learning Perspective, Turkish Online Journal of

Distance Education-TOJDE January 2018 ISSN 1302-6488 Volume: 19 Number: 1 Article 16

Renata Marciniak, (2018) International Review of Research in Open and Distributed Learning, Volume 19, Number 2 Autonomous University of Barcelona) (2nd ed.). Thousand Oaks, CA: Sage Publications.

Reisberg, L. A. (2007). Coming to terms with quality at Argentine universities: Institutional self study at ground level (Doctoral Dissertation). Available from ProQuest Dissertations \& Theses Database. (Publication No.3301803).

Steven J. McGahan, Christina M. Jackson, Karen Premer, (2015) Online Course Quality Assurance: Development of a Quality Checklist, University of Nebraska at Kearney Retrieved from: A Journal of Scholarly Teaching. Vol 10, (2015), 123-140

Veytia Bucheli, M., Chao González, M. (2013). Las competencias como eje rector de la calidad educativa. Revista electrónica de Divulgación de la Investigación, 4. Retrieved from http://portales. sabes.edu.mx/redi/4/

Wancai, Wu. (2008) Comparative Research on Quality Assurance in Distance Learning between China and UK - Case study of the CCRTVU and the OUUK Gansu Radio \& TV University, China. Retrieved from; file:///E:/Review\%20Materialof\%200wn\%20Study/Comparative\%20Study\%20QA\%20 DE.pdf

Zuhairi, A., Maria, K. and Mir, K. (2020), "Implementing quality assurance system for open and distance learning in three Asian open universities: Philippines, Indonesia and Pakistan", Asian Association of Open Universities Journal. October 2020 